\title{
An Analysis of the Appropriate Number of Workers in Elderly Care Hospital by Pathfinder in Korea
}

\author{
Hong-Sang Lee ${ }^{1}$, Ha-Sung Kong ${ }^{* 2}$ \\ ${ }^{1}$ Firefighter, BuanFirestation, BUAN, Republic of Korea \\ ${ }^{*}$ Fire and Disaster Prevention, Woosuk Univ., WANJU, Republic of Korea zerius@korea.kr ${ }^{1}$, \\ $\underline{119 \text { wsu@ naver.com }}{ }^{2}$
}

Article History: Received: 11 January 2021; Accepted: 27 February 2021; Published online: 5 April 2021

Abstract: This study estimated the appropriate number of employees that are able to evacuate all occupants
during the day time and nighttime through an evacuation simulation. During the daytime, 200 patients and 44
workers evacuated after 416 se This result showed that the number of workers was greater than the standard
number of daytime worker placements because this record was faster than the Korean Fire Department's average
arrival time of 430 seconds. Therefore, the appropriate number of workers during the daytime for all occupants
to escape within the Korean Fire Department's average arrival time of 430 seconds is 30 persons, 25 persons for
the standard evacuation time of 480 seconds, and 20 persons for the average time of flashover of 540 seconds.
During the nighttime, a total of 205 people, including 200 patients and 5 workers, needed 1,475 seconds to
evacuate. As this time exceeds the average time of flashover, it was shown that the number of workers was fewer
than the standard number of nighttime worker placements. Therefore, the appropriate number of workers at
nighttime is 35 persons for 430 seconds, 30 persons for 480 seconds, and 25 persons for 540 seconds Keywords: Pathfinder, Elderly care hospitals, Number of daytime workers, Number of nighttime workers, Evacuation time

\section{Introduction}

Elderly care hospitals in Korea are showing a continuous increase in number, from there being 1,103 in 2012 to 1,560 in 2018. [1] For every 1,000 elderly persons in Korea, the number of elderly care hospital beds is 36.7, which is more than ten times more than the OECD average of 3.6 and much more than the 9.5 in Japan, 2.5 in France, and 1.2 in the USA.[2] However, there have been as many accidents as there are elderly care hospitals. 21 people died in the fire that occurred in the elderly care hospital in OOO city in OOO region in 2014,[3] while 2 people died and 36 were injured in the fire that occurred in OOO city in OOO region in 2019[4]. As such, accidents have occurred consistently in living facilities for those weak to disasters.

Among medical facilities, elderly care hospitals are particularly susceptible to high numbers of casualties in fires due to the patients' many limitations in movement during the evacuation process. Although the Korean Fire Department and Fire Defense Headquarters are consistently carrying out evacuation drills with real-life simulation as well as special inspections for elderly care hospitals due to the high number of fire occurrences in such facilities, there are many difficulties during the evacuation drills due to the patients' physical limitations. During the daytime when there are higher numbers of workers, it is possible for them to help the patients evacuate the building but during the nighttime, effective evacuation is realistically impossible due to the limited number of workers.

When analyzing existing studies, Hyunwoo Kim et al. (2019)[5,15] did a comparative analysis of evacuation methods from 4 different elderly care hospitals and suggested a horizontal evacuation method consisting of 2 or more buildings, while Jongbeom Kim (2009)[6] carried out an evacuation simulation for the method of dispersing the evacuation routes and the method of installing ramps to calculate the evacuation time. HyunhoLee $(2019)[7,14]$ utilized Pathfinder to execute an evacuation simulation in a single-building elderly care hospital, through which he calculated the evacuation time used for the indications in the Ministry of Public Administration and Security inspection and amendments in the domestic Fire Services Act and Construction Act. Jongbeom Kim and Hyunho Lee's research have a similarity of having conducted an evacuation simulation on elderly care hospitals.

Existing studies have generally carried out evacuation simulations during the daytime when there are high numbers of workers at elderly care hospitalswhen assessing evacuation safety or focused on dispersing the evacuation route or installing ramps to improve delays in the evacuation during the nighttime. This study aims to calculatethe appropriate number of workers that will allow everyone's evacuation during the daytime when there are many workers and during the nighttime when there are few workers through evacuation simulations.

\section{Evacuation Simulation}

\subsection{Summary of the facilities}

The facility used in this study is an elderly care hospital located in $\mathrm{OOO}$ city in the $\mathrm{OOO}$ region that has a scale of 1 floor underground and 4 floors above ground. The building has a height of $17.313 \mathrm{~m}$, an area of 1,506.1 


\section{Research Article}

$\mathrm{m}^{2}$, and a total floor area of $6,930.96 \mathrm{~m}^{2}$. The 2nd and 3rd floors are used for group patient rooms and the 4th floor is used for individual patient rooms. Figure 1 shows the floor plan of B1, which is used for the medical gas room, food and materials storage room, kitchen, low-temperature storage room, cafeteria, machine room, electrical room, storage room, and medical supplies room. This floor was excluded from the study because there are no patient rooms there.

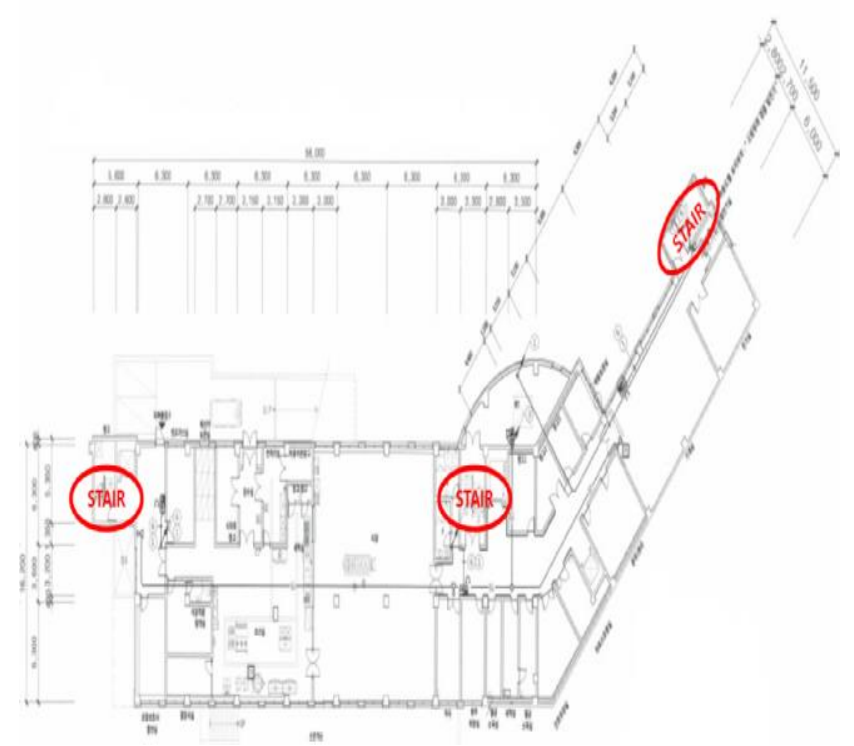

Figure 1. Floor plan of B1

Figure. 2 is the floor plan of the 1st floor. The 1st floor is used for the physical therapy room, doctor's offices, treatment room, medical lab, radiation room, and store. At the center of the building is the main entrance and exit and there are more 2 more at either end of the building. Since there are no inpatients on the 1st floor, this study chose not to place any patients on this floor during the nighttime and instead placed 1 radiologic technologist and 1 medical lab technologist. The 1 st floor was used only as an evacuation route to evacuate the building.

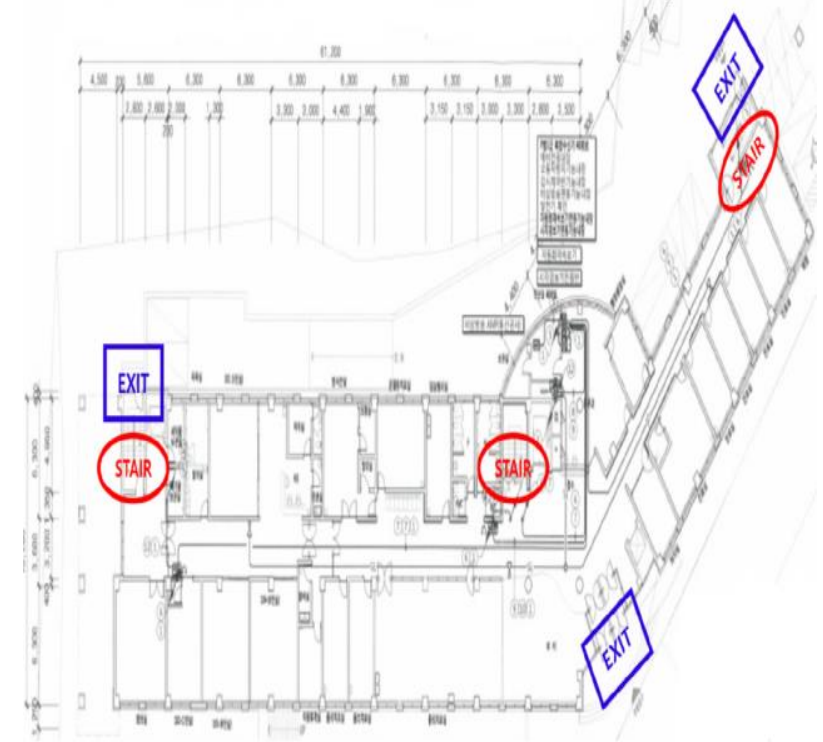

Figure 2. Floor plan of the 1st floor

Figure. 3 is the floor plan of the 2 nd floor. The 2 nd floor consists of 20 5-person patient rooms, employee lounge, showers, linen room, and pantry. There is a stairway at the center and on either side of the building. 


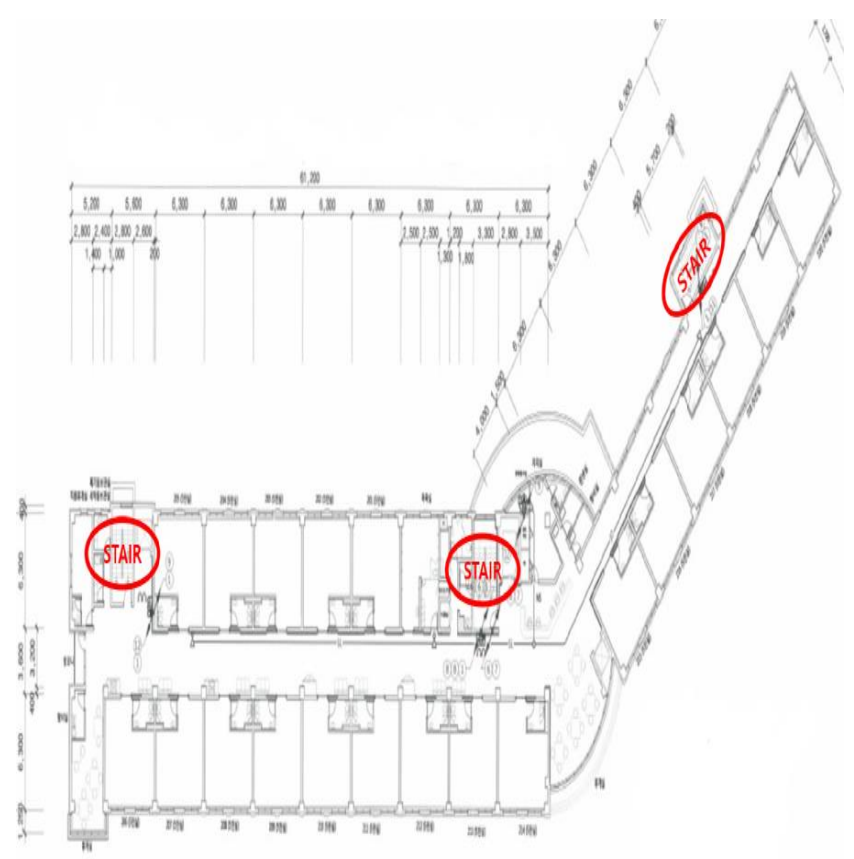

Figure 3. Floor plan of the 2nd floor

Figure. 4 is a floor plan of the 3rd floor. Same as the 2nd floor, it also consists of 20 5-person patient rooms, employee lounge, bathroom, linen room, and pantry. There is a stairwayat the center and on either side of the building, and the corridor has a width of $3.2 \mathrm{~m}$ and $2.7 \mathrm{~m}$.

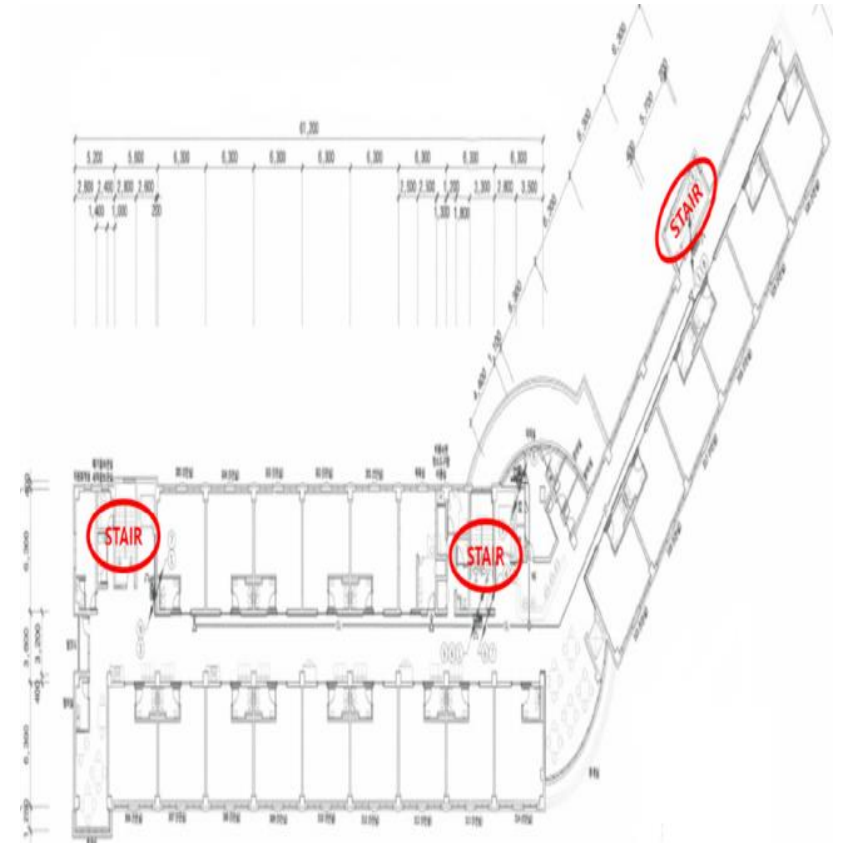

Figure 4. Floor plan of the 3rd floor

Figure. 4 is a floor plan of the 3rd floor. Same as the 2nd floor, it also consists of 20 5-person patient rooms, employee lounge, bathroom, linen room, and pantry. There is a stairwayat the center and on either side of the building, and the corridor has a width of $3.2 \mathrm{~m}$ and $2.7 \mathrm{~m}$.

\subsection{Input variables and input values}

2.2.1 Number of workers according to the number of patients 
When the number of beds is the standard, the patient capacity is a maximum of 200 patients -205 -person patient rooms on both the 2 nd floor and 3rd floor. In the case of doctors, this study chose to place 5 doctors in the facility according to a standard of there being 1 doctor for 40 patients, and no Korean medicine doctors were placed. There must be at least 1 nurse for 6 patients; thus, 34 nurses can be placed but, in accordance with the saving clause that nurse's aides can replace them as long as they do not exceed $2 / 3$ of the number of nurses, 12 nurses and 22 nurse's aides were placed. The elderly care hospital used in this study has a radiation room and medical lab on the 1st floor so 1 radiologic technologist and 1 medical lab technologistwere each placed, while 1 watch-keeping safety supervisor, 1 nutritionist, and 1 pharmacist could be placed additionally. The number of daytime workers according to the number of patients was 44, as shown in Table 1 below

Table 1. The number of daytime workers according to the number of patients

\begin{tabular}{|c|c|c|}
\hline Category & Worker allocations standard & $\begin{array}{l}\text { Number of } \\
\text { workers }\end{array}$ \\
\hline Doctor & $\begin{array}{l}\text { As per the average annual daily inpatient numbers, } 2 \text { doctors } \\
\text { for any number of inpatients until } 80 \text { per day, } 1 \text { doctor per } 40 \\
\text { inpatients when exceeding } 80 \text { (including Korean medicine } \\
\text { doctors). Every } 3 \text { outpatients are considered equivalent to } 1 \\
\text { inpatient. }\end{array}$ & 51 \\
\hline Dentist & N/A & \\
\hline $\begin{array}{l}\text { Korean } \\
\text { medicine doctor }\end{array}$ & $\begin{array}{l}\text { As per the average annual daily inpatient numbers, } 1 \text { doctor } \\
\text { per } 40 \text { inpatients (including doctors). Every } 3 \text { outpatients are } \\
\text { considered equivalent to } 1 \text { inpatient. }\end{array}$ & 0 \\
\hline Nurse & $\begin{array}{l}\text { As per the average annual daily inpatient numbers, } 1 \text { nurse } \\
\text { per } 6 \text { inpatients. Every } 12 \text { outpatients are considered equivalent } \\
\text { to } 1 \text { inpatient. }\end{array}$ & 12 \\
\hline Nurse's aide & Within the range of $2 / 3$ of the number of nurses & 242 \\
\hline $\begin{array}{l}\text { Medical } \\
\text { technician }\end{array}$ & Number necessary for each medical subject & $\begin{array}{l}1 \text { radiologic } \\
\text { technologist } \\
1 \text { medical lab } \\
\text { technologist3 }\end{array}$ \\
\hline $\begin{array}{l}\text { Facility safety } \\
\text { supervisor }\end{array}$ & 1 person or more & 1 \\
\hline Nutritionist & 1 person or more & 1 \\
\hline Pharmacist & 1 person or more & 1 \\
\hline \multicolumn{2}{|r|}{ Total } & 44 \\
\hline
\end{tabular}

Regarding the number of nighttime workers, when there are 200 patients, there can be 1 doctor, 3 nurses, and 1 watch-keeping safety supervisor. The number of nighttimeworkers according to the number of patients was 5 , as shown in Table 2 below.

\footnotetext{
${ }^{1}$ Doctors and nurses were placed under the assumption that there were no outpatients present.

${ }^{2}$ When calculatingfor 6 inpatients, there must be 36 nurses. However, in accordance with the saving clause that nurse's aides can replace them as long as they do not exceed $2 / 3$ of the number of nurses, 12 nurses and 22 nurse's aides were placed.

${ }^{3}$ The elderly care hospital used in this study has a radiation room and medical lab on the 1st floor so 1 radiologic technologist and 1 medical lab technologist were each placed.
} 


\section{Research Article}

Table 2. The number of nighttime workers according to the number of patients

\begin{tabular}{|c|c|c|}
\hline Category & Worker allocations standard & Number of workers \\
\hline Doctor & $\begin{array}{c}\text { In the case of doctors, dentists, and Korean medicine } \\
\text { doctors, 1 doctor for any number of inpatients until 300, 1 } \\
\text { additional doctor per 300 inpatients when exceeding 300. }\end{array}$ & 1 \\
\hline Nurse & $\begin{array}{c}1 \text { nurse for any number of inpatients until 80,1 additional } \\
\text { nurse per 80 inpatients when exceeding 80. }\end{array}$ & 3 \\
\hline $\begin{array}{l}\text { Facility safety } \\
\text { supervisor }\end{array}$ & 1 person or more & 1 \\
\hline Total & \multicolumn{2}{|l}{} \\
\hline
\end{tabular}

It can be observed that compared to the 44 workers during the daytime, there is a drastic decrease in the number of workers during the nighttime, only consisting of 5 persons. It is estimated that such decreases in workers will cause a higher probability of problems in fires or emergencies such as a delay in the evacuation.

\subsubsection{Placement of occupants}

Figure. 6 is an elevation drawing and floor plan of the patient placement. 5 patients were placed in 5-person patient rooms, while workers such as the doctors, nurses, and nurse's aides were placed in the corridor.

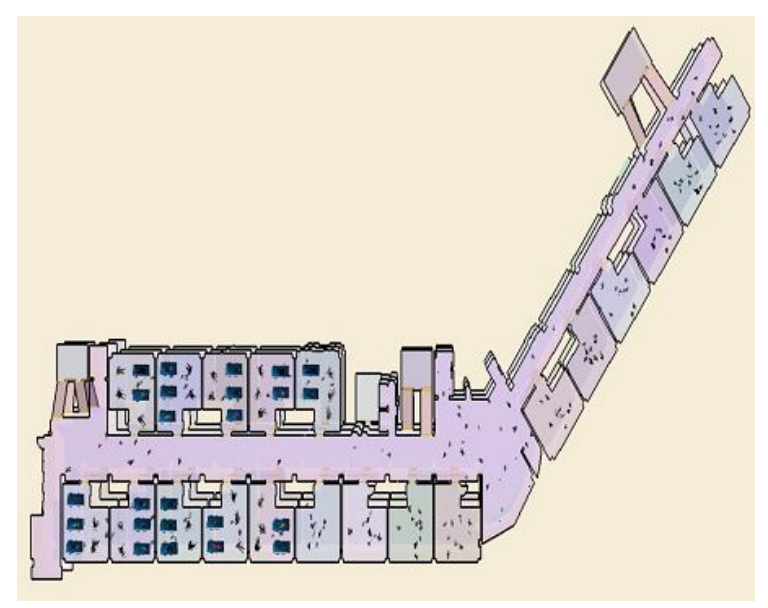

(a)

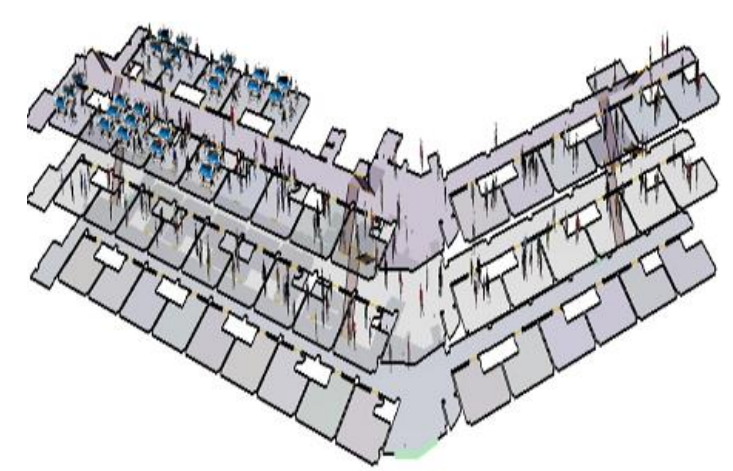

(b)

Figure 5. Placement of occupants 
(a) Floor plan, (b) Elevation drawing

\subsubsection{Physical characteristics of occupants}

As shown in Table 3 below, the physical characteristics of patients are regarding the age, sex, height, shoulder width, walking speed, etc. and it was written in reference to the 'Study on the Body Dimension of Koreans' by the National Statistics Office.[10] Eungsik Kim et al. (2016)[11] was referred to for determining the walking speed. Patients with dementia or advanced diseases were categorized as those that are unable to evacuate independently4 and 25 of the patients on the 3rd floor were categorized as such. Doctors, nurses, nurse's aides, and patients were placed on the 2nd and 3rd floors, while the radiologic technologist, medical lab technologist, nutritionist, and pharmacist were placedon the 1 st floor. The facility safety supervisor was placed on the 2 nd floor and patients unable to evacuate independently were placed on the 3rd floor.

Table 3. Physical characteristics of occupants placed on each floor

\begin{tabular}{|c|c|c|c|c|c|c|}
\hline Category & $\mathrm{x}^{\mathrm{Se}}$ & Age & $\begin{array}{l}\text { Height } \\
(\mathrm{cm})\end{array}$ & $\begin{array}{l}\text { Should } \\
\text { er width } \\
(\mathrm{cm})\end{array}$ & $\begin{array}{l}\text { Walking } \\
\text { speed } \\
(\mathrm{m} / \mathrm{s})\end{array}$ & $\begin{array}{l}\text { Number of } \\
\text { people } \\
\text { (Daytime/Nightti } \\
\text { me) }\end{array}$ \\
\hline Doctor & $\mathrm{M}$ & $\begin{array}{c}30 \sim \\
40\end{array}$ & 173.7 & 40.3 & 1.5 & $5 / 1$ \\
\hline Nurse & $\mathrm{F}$ & $\begin{array}{c}20 \sim \\
30\end{array}$ & 160.2 & 35.6 & 1.5 & $12 / 3$ \\
\hline Nurse's aide & $\mathrm{F}$ & $\begin{array}{c}50 \sim \\
55\end{array}$ & 156 & 35.9 & 1.3 & $22 / 0$ \\
\hline $\begin{array}{l}\text { Radiologic } \\
\text { technologist }\end{array}$ & M & $\begin{array}{c}30 \sim \\
40\end{array}$ & 173.7 & 40.3 & 1.5 & $1 / 0$ \\
\hline $\begin{array}{l}\text { Medical lab } \\
\text { technologist }\end{array}$ & M & $\begin{array}{c}30 \sim \\
40\end{array}$ & 173.7 & 40.3 & 1.5 & $1 / 0$ \\
\hline $\begin{array}{c}\text { Facility } \\
\text { safety supervisor }\end{array}$ & M & $\begin{array}{c}30 \sim \\
40\end{array}$ & 173.7 & 40.3 & 1.5 & $1 / 1$ \\
\hline Nutritionist & $\mathrm{F}$ & $\begin{array}{l}50 \sim \\
55\end{array}$ & 156 & 35.9 & 1.3 & $1 / 0$ \\
\hline Pharmacist & $\mathrm{F}$ & $50 \sim 55$ & 156 & 35.9 & 1.3 & $1 / 0$ \\
\hline Patient & $\mathrm{M}$ & $65 \sim$ & 164.4 & 37.9 & 0.9 & $75 / 75$ \\
\hline Patient & $\mathrm{F}$ & $65 \sim$ & 152.9 & 35.5 & 0.9 & $75 / 75$ \\
\hline \multirow{2}{*}{\begin{tabular}{l}
\multicolumn{1}{c}{ Patient } \\
unable \\
evacuate \\
independently
\end{tabular}} & \multirow{2}{*}{$\mathrm{M}$} & \multirow{2}{*}{$65 \sim$} & \multirow{2}{*}{164.4} & \multirow{2}{*}{37.9} & $\begin{array}{l}\text { Bedridden } \\
\text { patient }^{5}\end{array}$ & $13 / 13$ \\
\hline & & & & & $\begin{array}{l}\text { Wheelchair: } \\
0.87\end{array}$ & $12 / 12$ \\
\hline \begin{tabular}{l}
\multicolumn{1}{c}{ Patient } \\
unable \\
evacuate \\
independently
\end{tabular} & $\mathrm{F}$ & $65 \sim$ & 152.9 & 35.5 & $\begin{array}{l}\text { Bedridden } \\
\text { patient }\end{array}$ & $12 / 12$ \\
\hline
\end{tabular}

${ }^{4}$ Patients that are unable to evacuate independently: There are a total of 50 patients of dementia or advanced diseases on the $3^{\text {rd }}$ floor, among which 25 are unable to move independently because they are in a wheelchair or moving bed. There are 100 occupants on both the $2^{\text {nd }}$ and $3^{\text {rd }}$ floor, among which $50 \%$ are men and $50 \%$ are women. Among the patients of dementia or severe diseases on the $3^{\text {rd }}$ floor, 25 are in a wheelchair and 25 are in a moving bed. Among them, 13 females and 12 men are able to move independently in the wheelchair, while a total of 25 patients were hypothesized to be unable to move independently.

${ }^{5}$ Bedridden patients are unable to move independently and cannot walk so their walking speed is not applicable. 


\subsubsection{Behavioral characteristics of occupants}

When executing the evacuation simulation, behavioral characteristics are a very important component alongside physical characteristics. Due to there being patients that are unable to evacuate independently in this elderly care hospital, the behavioral characteristics of occupants aiding such patients are important.

The Pathfinder program used in this study has a feature called 'Assisted Evacuation Team', a behavioral characteristic that helps those who are unable to evacuate independently. Persons who are given this behavioral characteristic helps those who are unable to evacuate independently. For this study, the doctors, nurses, nurse's aides, radiologic technologist, medical lab technologist, and facility safety supervisor were set as the Assisted Evacuation Team. The behavioral characteristic of the nutritionist and pharmacist was set as 'Self-evacuation' so that they would evacuate independently. Table 4 below summarizes the occupants' behavioral characteristics.

Table 4. Behavioral Characteristics of Occupants

\begin{tabular}{|c|c|}
\hline Category & Behavioral Characteristic \\
\hline Doctor & Assisted Evacuation team \\
\hline Nurse & Assisted Evacuation team \\
\hline Nurse's aide & Assisted Evacuation team \\
\hline Radiologic technologist & Assisted Evacuation team \\
\hline Medical lab technologist & Assisted Evacuation team \\
\hline Facility safety supervisor & Assisted Evacuation team \\
\hline Nutritionist & Self-evacuation \\
\hline Pharmacist & Self-evacuation \\
\hline Patients able to evacuate independently & Self-evacuation \\
\hline Patients using a wheelchair & Self-evacuation \\
\hline Patients unable to evacuate independently & Wait Assisted Evacuation team \\
\hline
\end{tabular}

Behavioral characteristics in this study can be categorized into 3 groups. The first a is re occupants who evacuate independently, the second is occupants that are almost immobile and cannot evacuate without help, and the third is occupants that help those that cannot evacuate without help.

\subsection{Scenario composition}

\subsubsection{Analysis of the evacuation time and number of workers according to the number of daytime} workers

In the elderly care hospital used in this study, there are 200 patients and 44 workers in the daytime. This study aims to analyze the evacuation time and accordingly calculate the appropriate number of workers in the daytime when there is a relatively larger number of workers.

\subsubsection{Analysis of the evacuation time and number of workers according to the number of nighttime} workers

Because only the minimum number of workers necessary for emergency treatment are present in the nighttime, there are 5 workers present. This study aims to analyze the evacuation time in case of a fire during the nighttime when a small number of workers are present, and accordingly calculate the appropriate number of workers.

\subsection{Assessment Standard}

The possible evacuation time for the occupants of the facility is shown in Table 5 below.[12] In this study, with the hypothesis that this is an elderly care hospital equipped with alarm facilities such as a fire alarm and that acting persons are untrained workers, the possible evacuation time was calculated to be 8 minutes or less. During the daytime, having taken into consideration that the decreased credibility of the alarm system due to past instances of non-fire alarms and that there may be delays due to the patients' older age, the evacuation was set to begin 60 seconds after the commencement of the fire. During the nighttime, having taken into consideration that patients have been prescribed sleeping pills for stabilization, possible delay in recognizing the fire due to sleep, and difficulties in evacuation compared to the daytime, the evacuation was set to begin 120 seconds after the commencement of the fire. 


\section{Research Article}

Table 5. Standard for Possible Evacuation Time

\begin{tabular}{|c|c|}
\hline Building usage & Possible evacuation time \\
\hline $\begin{array}{c}\text { Hospital, Elderly care hospital, Other public accommodations } \\
\text { (Most inhabitants need help from their surroundings) }\end{array}$ & 8 min. or less \\
\hline
\end{tabular}

\section{Results and Evaluation}

The elapsed time of evacuation was measured based on the 7 minutes 10 seconds (the average time for the Korean Fire Department to arrive on site), 8 minutes (the standard for possible evacuation time), 9 minutes (the average time of flashover), and the time when everyone in the building was safely evacuated. In 2019, it took an average of 7 minutes 10 seconds nationally for the Korean Fire Department to arrive at the site of a fire in Korea; thus, the evacuation elapsed time of evacuation was set to 7 minutes 10 seconds [13]. The time of flashover can be as short as 2-3 minutes or less and can be up to 10 minutes or more. After a fire safety evaluation of the volume of inflammable materials, the size and location of openings, the size and building height of the compartments, and the interior materials and furniture, it was observed that the level of fire safety was high. The time of flashover was set as approximately 9 minutes from the initial occurrence of the fire and hence, the elapsed time of evacuation was set as 9 minutes.

\subsection{Evacuation time according to the number of daytime workers}

It was hypothesized that during the daytime, 200 patients and 44 workers would be present in the building. Results of the evacuation simulation revealed that all 200 patients and 44 workers were able to evacuate after 416 seconds. This time is faster than 430 seconds, the average arrival time on site of the Korean Fire Department, and also the shortest elapsed time of evacuation. Figure. 6 below shows the results of the evacuation simulation during the daytime when 44 workers are present.

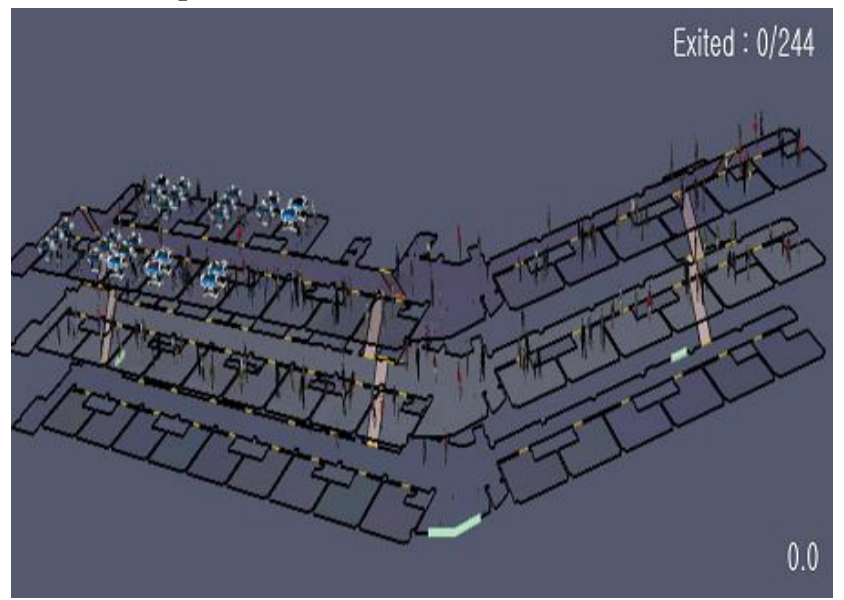

(a)

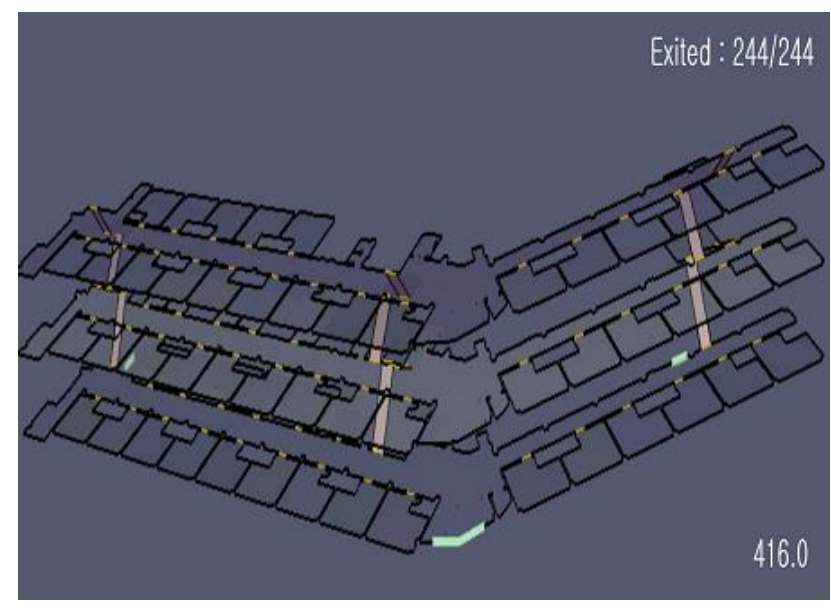

(b)

Figure 6. Changes in the number of escaped persons in case of a fire during the daytime when 5 workers are present, according to the elapsed time 
(a) Before evacuation, (b) After 416 seconds (RSET)

\subsection{Appropriate number of workers during the daytime}

After executing an evacuation simulation based on the 44 workers that are present during the daytime, it was observed that all 200 patients and 44 workers were able to evacuate after 356 seconds. This time is faster than 430 seconds, the average arrival time on site of the Korean Fire Department, and thus can be seen as inefficient worker placement in terms of evacuation time and workforce operation. In order to increase efficiency by decreasing the number of daytime workers and determining the number of workers that can evacuate within the given time, it was observed that the appropriate number of workers during the daytime for all occupants to escape within the Korean Fire Department's average arrival time of 430 seconds is 30 persons, 25 persons for the standard evacuation time of 480 seconds, and 20 persons for the average time of flashover of 540 seconds. Table 6 below shows the changes in the number of escaped persons per number of workers placed in the daytime, according to the elapsed time.

Table 6. Changes in the number of escaped persons per number of workers placed in the daytime, according to the elapsed time

\begin{tabular}{|c|c|c|c|c|}
\hline \multirow{2}{*}{$\begin{array}{l}\text { Number of } \\
\text { workers }\end{array}$} & \multicolumn{3}{|c|}{ Number of escaped persons according to the elapsed time } & \multirow{2}{*}{$\begin{array}{r}\text { Total number of } \\
\text { evacuated persons } \\
(200 \text { patients }+ \\
\text { Number of workers }\end{array}$} \\
\hline & After 430 seconds & $\begin{array}{l}\text { After } 480 \\
\text { seconds }\end{array}$ & $\begin{array}{l}\text { After } 540 \\
\text { seconds }\end{array}$ & \\
\hline 20 & $\begin{array}{c}195 \\
(89 \%) \\
\end{array}$ & $\begin{array}{c}211 \\
(96 \%)\end{array}$ & $\begin{array}{c}220 \\
(100 \%)\end{array}$ & 220 \\
\hline 25 & $\begin{array}{c}212 \\
(87 \%)\end{array}$ & $\begin{array}{c}225 \\
(100 \%)\end{array}$ & & 225 \\
\hline 30 & $\begin{array}{c}230 \\
(100 \%)\end{array}$ & & & 230 \\
\hline
\end{tabular}

\subsection{Evacuation time according to the number of nighttime workers}

The evacuation simulation hypothesized that there were 200 patients and 5 workers during the nighttime. The evacuation simulation results revealed that a total of 205 persons, including 200 patients and 5 workers, were able to evacuate after 1,475 seconds. Figure. 7 below shows the evacuation simulation results when there are 5 workers during the nighttime.

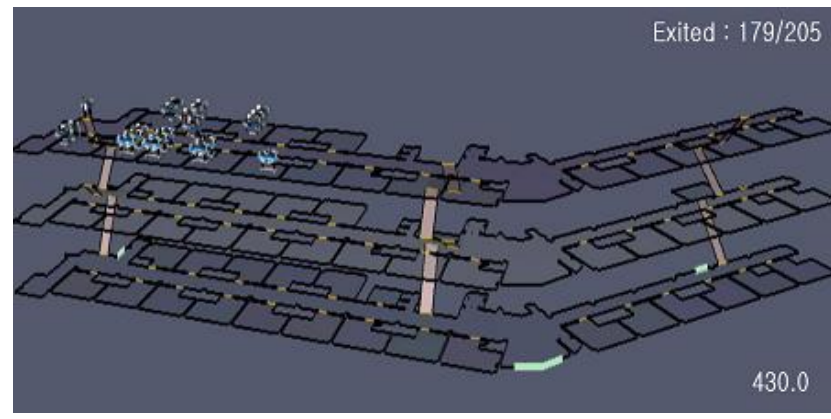

(a)

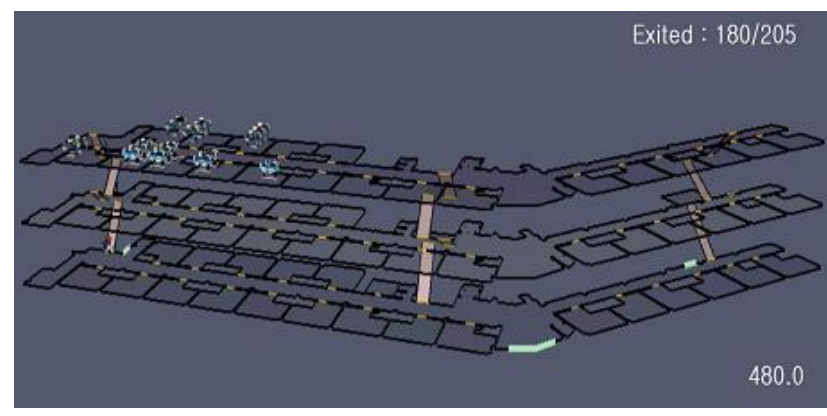

(b) 


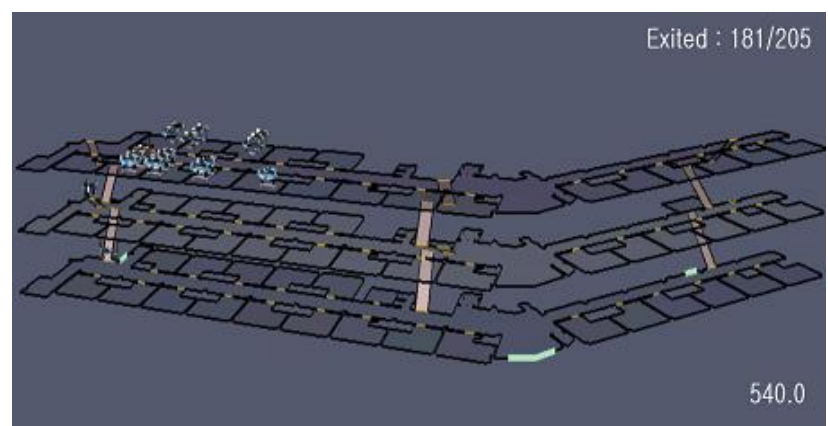

(c)

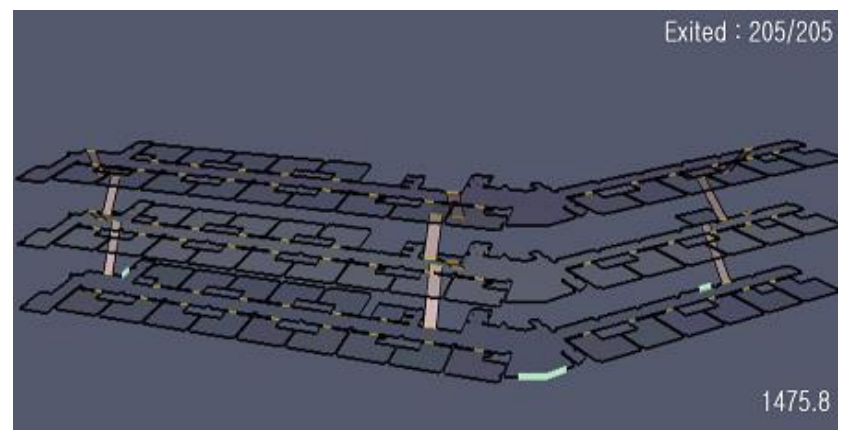

(d)

Figure 7. Changes in the number of escaped persons in case of a fire during the nighttime when 5 workers are present, according to the elapsed time

(a) After 430 seconds, (b) After 480 seconds, (c) After 540 seconds, (d) After 1,475 seconds (RSET)

\subsection{Appropriate number of workers during the nighttime}

An evacuation simulation was executed to determine the number of workers necessary for all occupants to evacuate within the set time during the nighttime in case of fire, incrementally increasing the number of nighttime workers. As a result, it was revealed that the appropriate number of workers during the nighttime for all occupants to escape within the Korean Fire Department's average arrival time of 430 seconds is 35 persons, 30 persons for the standard evacuation time of 480 seconds, and 25 persons for the average time of flashover of 540 seconds. Table 7 below shows the changes in the number of escaped persons per number of workers placed in the nighttime, according to the elapsed time.

Table 7. Changes in the number of escaped persons per number of workers placed in the nighttime, according to the elapsed time

\begin{tabular}{|c|c|c|c|c|}
\hline \multirow{2}{*}{$\begin{array}{l}\text { Number of } \\
\text { workers }\end{array}$} & \multicolumn{3}{|c|}{ Number of escaped persons according to the elapsed time } & \multirow{2}{*}{$\begin{array}{r}\text { Total number of } \\
\text { evacuated persons } \\
(200 \text { patients }+ \\
\text { Number of workers }\end{array}$} \\
\hline & After 430 seconds & After 480 seconds & After 540 seconds & \\
\hline 20 & $189(86 \%)$ & $192(87 \%)$ & $206(94 \%)$ & 220 \\
\hline 25 & $195(87 \%)$ & $216(96 \%)$ & $225(100 \%)$ & 225 \\
\hline 30 & $221(96 \%)$ & $230(100 \%)$ & & 230 \\
\hline 35 & $235(100 \%)$ & & & 235 \\
\hline
\end{tabular}

\section{Conclusions}

Through an evacuation simulation, this study calculated the appropriate number of workers for all occupants to evacuate safely during the daytime and nighttime.

(1) It was shown that during the daytime, all 200 patients and 44 workers evacuated after 416 seconds of evacuation, revealing a faster evacuation time than the 430 seconds it takes for the Korean Fire Department to arrive on site; therefore, there were more workers than the standard of worker placement.

(2) It was shown that the appropriate number of workers during the daytime for all occupants to escape within the Korean Fire Department's average arrival time of 430 seconds is 30 persons, 25 persons for the standard evacuation time of 480 seconds, and 20 persons for the average time of flashover of 540 seconds. 
(3) It was shown that a total of 205 persons, including 200 patients and 5 workers, were able to evacuate after 1,475 seconds during the nighttime. This time exceeds the average time of flashover; therefore, there were fewer workers than the standard of worker placement.

(4) It was shown that the appropriate number of workers during the nighttime for all occupants to escape within the Korean Fire Department's average arrival time of 430 seconds is 35 persons, 30 persons for the standard evacuation time of 480 seconds, and 25 persons for the average time of flashover of 540 seconds.

In conclusion, it was revealed that the required number of workers during the nighttime is more than that which is needed during the daytime for safe evacuation. This study has the limitation of excluding the comparative analysis of various situations in which fire extinguishing facilities such as sprinklers are operating. Therefore, there is a necessity for continued research on evacuation time in relation to fire extinguishing facility operation.

\section{References}

1. Health insurance review \& Assessment service, Results of the 2018 Inpatient Care Benefit Assessment for Nursing Hospitals, pp. 4, 2019.

2. The Medicaltoday, 2019.12.23. http://www.mdtoday.co.kr/mdtoday/index.html?no=373366

3. The Kyunghyang Shinmun, 2014.05.28. http://news.khan.co.kr/kh_news/khan_art_view.html?artid=201405280822161\&code=940202

4. The KBS, 2019.09.24. http://news.kbs.co.kr/news/view.do?ncd=4289479\&ref=A

5. H. W. Kim, S. W. Park, H. J. Lee, Y. A. Kim, A study on fire evacuation countermeasures for patients in elderly care hospital - Best practices in Daejeon area focused on elderly care hospital, Korea Institute of Ecological Architecture and Environment, pp. 197, 2019.

6. J. B. Kim, A Study on Safety Assessment of the Evacuation at the Aged Care Hospital, Master degree paper. Dongshin University, Graduate School of Arts and Science, Department of Fire Service Administration, pp. 74-79, 2009.

7. H. H. Lee, A Study on Improvement of Evacuation Time in the Elderly Care Hospital by Evacuation Simulation Program, Master degree paper. Yeonsei University, Graduate School of Engineering, Major in Disaster Prevention and Safety Management, pp. 78-81, 200.

8. Korea Ministry of Government Legislation, $\ulcorner$ Medical law Enforcement Rules $\lrcorner$ Article 38, [supplementary table 5], [supplementary table 6], amended by April 24, 2020.

9. Korea Ministry of Government Legislation, $\ulcorner$ Medical law Enforcement Rules $\lrcorner$ Article 38, Article 39-8, amended by April 24, 2020.

10. Statistics Korea, Korean Body Size Survey: Statistics of 120 sites (Male),

11. http://kosis.kr/statHtml/statHtml.do?orgId=115\&tblId=TX_115190170\&conn_path=I2

12. Statistics Korea, Korean Body Size Survey: Statistics of 120 sites (Female),

13. http://kosis.kr/statHtml/statHtml.do?orgId=115\&tblId=TX_115190171\&conn_path=I2

14. E. S. Kim, J. S. Lee, J. H. Kim, M, H, Kim, "A Study on Walking Speed of the Disabled by Welfare Center Classification”, Journal of the Korean Society of Safety, Vol. 31, No. 5, pp. 124-132, 2016.

15. Korea Ministry of Government Legislation, 「Performance-oriented design methods and standards for firefighting facilities, etc. $\lrcorner$ [Supplementary table 1], amended by July 26, 2017.

16. National Fire Data System, Status of Fire Truck Arrival at Fire Site. https://www.nfds.go.kr/.

17. Athiyaman, A., \&Magapa, T. (2019). Market Intelligence From The Internet: An Illustration Using The Biomass Heating Industry. International Journal of Economics and Finance Studies, 11(1), 1-16.

18. Basilgan, M., \&Akman, A. S. (2019). An Empirical Analysis On The Impact Of The Foreign Direct Investments On Export Performance: Turkey Case. International Journal of Economics and Finance Studies, 11(2), 89-105. 